\title{
Ontological Engineering for Methodological Support of Research into Energy-related Anthropogenic Impact of the Environment
}

\author{
Tatyana Vorozhtsova $^{1}$, Elena Maysyuk $^{2}$, Irina Ivanova $^{2}$ \\ ${ }^{1}$ Melentiev Energy Systems Institute SB RAS, Department of Artificial Intelligence Systems in Energy, Irkutsk, Russia \\ ${ }^{2}$ Melentiev Energy Systems Institute SB RAS, Laboratory of Energy Supply to Off-grid Consumers, Irkutsk, Russia
}

\begin{abstract}
Ontological engineering is performed for studies on the environmental impact of energy objects. The work was carried out within the framework of the project supported by the Russian Foundation of Basic Research "Methods of building an ontological knowledge space for intelligent decision-making support in the energy sector and environment, in terms of the quality of life". The study proposes developing a set of interconnected ontologies with the view to harmonizing terminology of different subject domains for research and decision support. The basic terminology used to examine the environmental impact of energy objects and to perform appropriate quantitative assessments is considered. Semantic methods are proposed, in particular, an ontological analysis of the subject domain, to systematize environmental assessments and establish relationships between the main indicators describing the impact of energy sector activity on the components of the environment. The ontological approach allows systematizing and visualizing the relationship between the components of the environment, energy objects and their characteristics, and impact factors. Ontological engineering made it possible to build a sequence of research and systematize the methodology used to assess the energy-related environmental impact.
\end{abstract}

Keywords. Anthropogenic impact, anthropogenic factor, ontology, energy objects, ontological engineering, ontological approach.

\section{Introduction}

Assessment of the environmental impact of energy objects is undoubtedly an urgent issue. Melentiev Energy Systems Institute of Siberian Branch of the Russian Academy of Sciences works on the use of semantic methods, including ontological modeling of this subject domain. Currently, a research team of the Institute, with the support of the Russian Foundation of Basic Research, is implementing the project "Methods of building an ontological knowledge space for the intelligent decision-making support in the energy sector and environmental science with regard to the quality of life". This project suggests a systems analysis of a methodology for the studies of the environmental impact of energy. The first stage of these studies involves an analysis of the existing methods and models for research aimed at harmonizing the sources of information and systematizing the indices used to implement these methods.

In general, the assessment of the impact of the energy sector in this study means a comprehensive investigation of the relationship between the processes that occur at various levels of the phenomena studied: from the impact of energy objects, which subsequently creates anthropogenic pollution, to the consequences in the form of changes in the natural environment components.

Ontological engineering involves the development of ontologies providing analysis and coordination of terminology of subject domains of energy and environment that intersect in our research, the establishment of relationships between the terms used, and structuring of the information necessary for this.

The ontological engineering performed previously in the field of the research into the interaction between energy and geo-environment [1] reflects the diversity of anthropogenic factors at different stages of the heat and electricity production process. Anthropogenic impacts include all effects produced by human activities on the environment.

This paper analyzes the methods applied today to assess the environmental impact of energy objects in order to structure the methodology necessary for this. The main attention is paid to the influence of energy generating facilities [2]. 


\section{The energy-related environmental impact and classification of anthropogenic factors}

In recent decades the anthropogenic pollution of the environment has been global in nature [3 - 6]. Today the human impact on nature is associated with changes in:

- landscape and structure of the earth's surface;

- composition of the biosphere;

- thermal balance of the planet or its regions;

- flora and fauna.

Anthropogenic impact leads to a change in the state of the environment, where new components (pollutants) appear. The objects of pollution are the atmosphere, soil, water, plants, animals, and microorganisms. Sources of pollution are industrial facilities, including energy and utility facilities.

The energy sector is one of the most serious sources of pollution. The anthropogenic impact of energy sector on the biosphere is seen in all stages of energy production - in the extraction and transportation of resources, in the production, transmission, and consumption of energy.

The functioning of energy objects affects all components of the environment - the atmosphere, water bodies, flora and fauna, and humans. Energy production is associated with landscape changes, the formation of quarries and dumps. The transportation of coal leads to the spread of harmful substances in the atmosphere and soil. Typical harmful impurities due to the burning of solid fossil fuels are soot, ash, carbon oxides, sulfur, nitrogen, heavy metal compounds, water vapor, and other substances, including carcinogens. The transmission of electric power causes electromagnetic fields near power lines. The operation of power plants is always associated with heat emissions. In addition, large areas of land are withdrawn from economic use.

In general, the harmful effects of energy objects on the environment are assessed based on a systems analysis of all interconnected processes at various stages of electricity and heat production.

In this regard, it is necessary to take into account the types, sources, levels of the influence of various anthropogenic phenomena and factors. In literature, there are many classifications of anthropogenic factors according to different features [5]. For example, according to the general nature of the impact, i.e. a change in landscapes, withdrawal of natural resources, and environmental pollution. The objects of influence are the surface of the earth and mineral resources, soil and vegetation, water bodies and atmosphere, as well as the microclimate of the environment, the animal world, and humans. Quantitative characteristics of the impact include spatial scales (global, regional, local), the severity of impact, the degree of danger, and others.

There is a classification of the anthropogenic factors [6] according to the following features:

- $\quad$ by nature mechanical, physical, chemical, landscape;

- by physical properties - substance, process, phenomenon, object;
- by the persistence of changes that occur in the environment (nature) - temporary reversible changes, relatively irreversible changes, absolutely irreversible changes, anthropogenic stress of ecosystems;

- by the ability to accumulate - only at the time of production, for a long time;

- by frequency - continuously acting factor, periodic factor, sporadic factor;

- by the ability to migrate - non-migratory, migrating with streams of water and air, migrating with sources, migrating independently.

\section{Ontological engineering}

Ontological engineering is the process of designing and developing ontologies to analyze the domain knowledge, including its extraction, structuring, and formalization.

The ultimate goal of ontological engineering is a formalized representation of the domain knowledge for its further use in the knowledge work and knowledge management system [7 - 9].

In this study, the development of ontologies is necessary to:

- clarify and harmonize terminology of different subject domains - environment and energy;

- define basic concepts in the study of the environmental impact of the energy sector;

- $\quad$ systematize the relationships between the concepts and identify classes and subclasses of ontologies;

- $\quad$ structure the knowledge and information in the context of the ongoing study.

In this stage, a set of ontologies classified as non-formal is developed. They are the result of discussion and clarification of terms and their definitions, identification of basic concepts, and description of the relationship between the concepts. As for the purpose of their development, the proposed ontologies are of applied nature, since they describe a conceptual model of the objective of the study on the environmental impact of the energy sector. For illustration, the ontologies are presented graphically using CmapTools. This provides the possibility of interaction between specialists of different subject domains.

The presentation of the ontologies in the formats necessary for computer processing is provided for further use of the developed system of ontologies.

This study considers the following basic concepts related to the energy-related environmental impact: energy object, energy resource, and component of the environment, which is affected due to the occurrence of an anthropogenic factor. Based on the analysis of methods existing for the assessment of this impact, we propose separate consideration of the concepts of anthropogenic factor, anthropogenic impact, anthropogenic pollution, and its consequences.

The definitions of these basic concepts are given below.

Energy object is a combination of energy plants and auxiliary devices, which are integrated territorially and technologically, and designed to jointly perform production and engineering tasks. 
Energy resource is an energy carrier, which is or can be used in the energy sector at a given level of technology or in the foreseeable future of its development.

Component of the environment is all that helps to ensure and maintain favorable conditions for the preservation of life on Earth. This category includes the earth, mineral resources, soil, flora and fauna, oceans, atmosphere, and near-Earth outer space.

The anthropogenic factor is the cause of the anthropogenic impact on the natural environment, due to the process and operating conditions of the object, and its characteristic features. In terms of energy objects, anthropogenic factors are understood as emissions, waste, radiation, noise, vibration, radiance, etc. The anthropogenic factor depends on the type and kind of energy resource and type of technologies of the energy object.

The anthropogenic impact is a consequence of the anthropogenic factor, the process of the influence of economic or other human activity on the components of the environment. Anthropogenic factors of energy objects have physical, chemical, biological, electromagnetic, noise, and radiation effects on various components of the environment. The level of anthropogenic impact is determined by the anthropogenic load, which depends on the magnitude of the factor, environmental conditions, and duration of exposure.

Anthropogenic pollution is a result of changes in the components of the environment caused by anthropogenic impact. The degree of pollution depends on the anthropogenic load and determines the concentration of harmful substances in the components of the environment. The degree of pollution is determined by the composition of harmful substances, the ability to adapt to anthropogenic impact and its duration.

The consequence is a result of anthropogenic pollution. This may be the withdrawal of land, land depletion, landscape disturbance, destruction of vegetation, acidification of soil, diseases of animals and humans, drying out of water bodies, etc.. Figure 1 shows the basic relationships between the basic concepts.

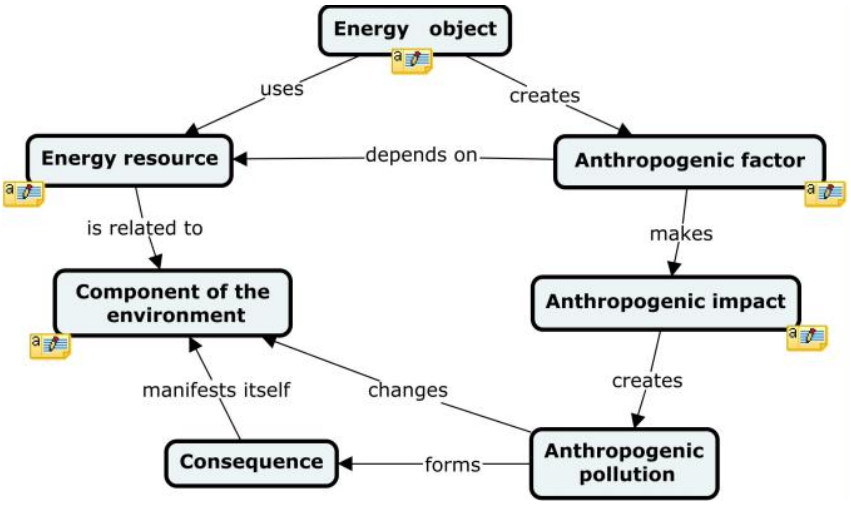

Fig. 1. Metaontology of the environmental impact of energy sector

In the study, these concepts are considered as the base classes of metaontology. The next level of ontologies details the basic concepts, clarifies relationships and reflects the properties of each of them.

The concept of anthropogenic factor is the most important in this study. The anthropogenic factor results from the operation of an energy object, depending on the energy resource used. It is characterized by some properties, such as frequency of exposure, ability to migrate, and has one of the states. Anthropogenic factors include emissions, discharges, waste, noise, and radiation. A detailed definition of the anthropogenic factor concept is shown in Figure 2.

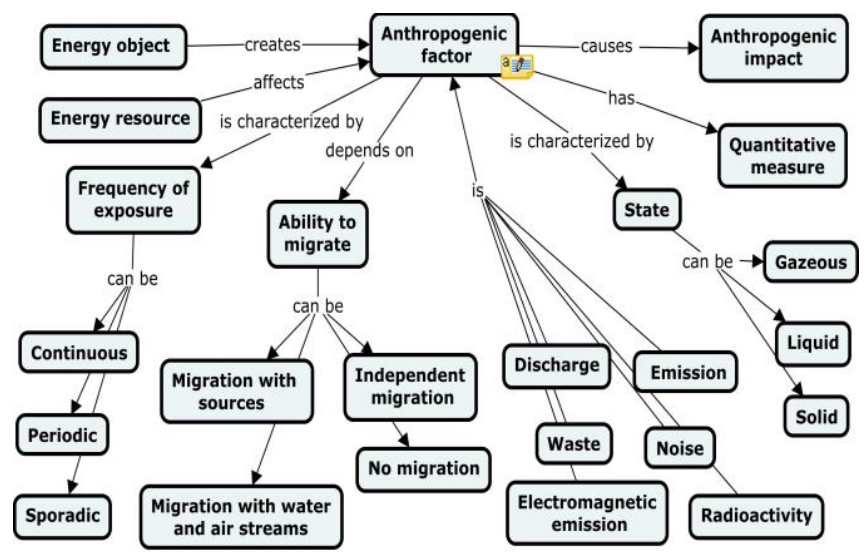

Fig. 2. Ontology of the anthropogenic factor

Each of the concepts used has been detailed similarly. For example, the concept of anthropogenic pollution, as noted earlier, is a consequence of anthropogenic impact.

Anthropogenic impact forms the consequence of anthropogenic pollution. Its effect on the component of the environment is measured by the level of pollution and depends on the anthropogenic load. It is also necessary to take into account the properties of frequency and the ability to be accumulated, as shown in Figure 3.

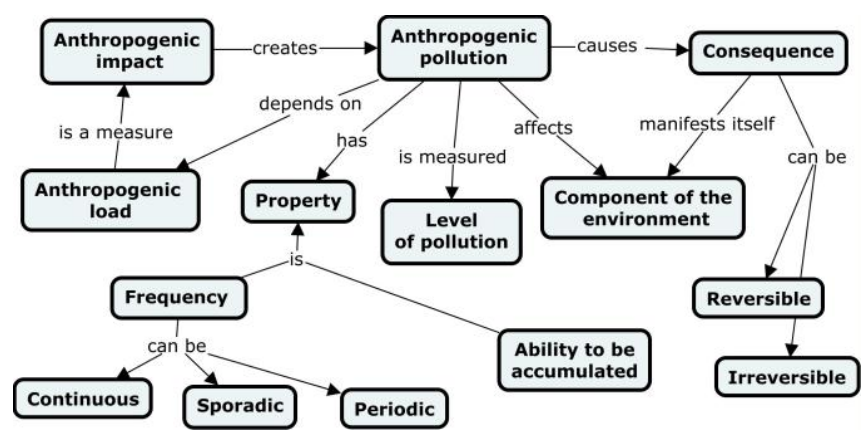

Fig.3. Ontology of anthropogenic pollution

Thus, a thorough examination of each concept makes it possible to factor in all the details in the study of the subject domain, classify terms, and establish relationships to take relevant information.

The next levels of the ontology system deal with the types of energy objects, their technical and production characteristics necessary for the implementation of methods for assessing the energy-related environmental impact.

The developed system of ontologies is the basis for an intelligent system of decision support and the creation of databases and knowledge bases.

\section{Methodological support of the studies on the environmental impact of energy objects}

The methodological support in this study means a method of quantifying the relationships between the 
concepts and phenomena that reflect the environmental impact of energy objects.

Considering successively the metaontology in figure 1, it is necessary to clarify that the anthropogenic factor implies the operation of energy objects, which causes changes in the composition, structure, and properties of the environment components: atmosphere, water bodies, soils, and living organisms.

In this regard, the initial disturbance from the operation of energy objects is the appearance of irrelevant impurities and changes in the state of the components of the environment. Accordingly, a quantitative measure of the anthropogenic factor for each component of the environment is a respective set of characteristics/indices with their units of measurement. The existing approved methods for calculating emissions, discharges, waste, etc., can serve as methodological support for the quantitative assessment (Figure 4).

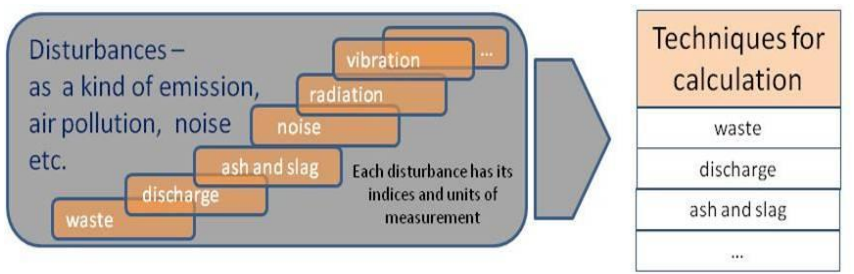

Fig. 4. Methodological support for the quantitative assessment of the anthropogenic factor

In general, the anthropogenic factor of the energy object operation is related to the anthropogenic impact through disturbance. The anthropogenic impact is a change in the natural environment components because of disturbances.

At the same time, quantitative indicators of disturbances in combination with the characteristics of the properties of the environment components make it possible to determine whether or not there is an effect for a particular component of the environment, whether it is high or insignificant.

The properties and state of the environment components are described by climatic models, and the "behavior" of incoming impurities is described by models of their distribution.

A quantitative measure of impact is the anthropogenic load, which is assessed qualitatively as high, medium or low.

The methodological support for the study of anthropogenic impact is associated with the collection and analysis of data on the current state using official reports on the state of the environment. The methodological support also includes certain climatic "behavioral" models that describe physical, thermodynamic, and chemical processes in the natural environment components for a particular territory.

The methodological support contains the methods of:

- assessing the current (background) state of the environment component;

- analyzing and collecting the information about the pollutant, its properties, hazard/ harmfulness;

- $\quad$ assessing the adaptation, self-cleaning and self-healing abilities of the environment components.
The pollution of the environmental components is formed depending on the severity of the impact (anthropogenic load) and duration. The pollution is determined by the composition of harmful substances, their hazard class, and the ability to be accumulated in the component of the natural environment.

Assessment of the extent to which the environment components are polluted due to the impact suggests determining the number of harmful substances, which "falls out" on the surface and forms the levels of pollution.

This stage employs the models of the spread of harmful impurities with the view to determining the quantity of impurities washed out from the atmosphere and then the density of deposition of the pollutants on the surface of soils and water bodies, as well as potential volumes of their penetration into living organisms - plants, animals, humans (Figure 5).

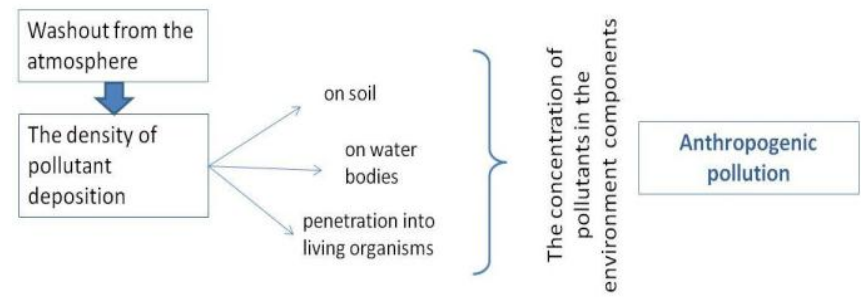

Fig. 5. Scheme of the formation of anthropogenic pollution depending on the density of the deposition of pollutants

Accordingly, a quantitative measure of anthropogenic pollution is the concentration of pollutants in the environment components, given the density of their deposition.

Thus, anthropogenic pollution due to disturbances and the impact of energy objects forms consequences for the environment components. The results of the consequences are the changes that occur: withdrawal, depletion, violation, destruction, acidification, disease, drying, etc.

Methodological support for assessing the consequences is the systematization of existing quality standards for each component of the environment. A comparison of norms and actual pollution levels in the form of concentrations and density of deposition will allow us to assess the environmental impact of energy objects. The quantitative measure of the consequences, which is assumed in this study, is a comparison of concentrations with the existing maximum permissible concentration standards - their exceedance or non-exceedance in the environment components.

Thus, the combination of these four research components makes it possible to build the methodological support for assessing the environmental impact of energy objects (Table 1). In some cases, statistical materials, reporting data on the activities of energy companies and government reports on the state of the environment both nationally and regionally can also serve as methodological support.

\section{Conclusion}

The paper presents a study on the energy-related environmental impact in the form of ontologies and 
descriptions of concepts and definitions corresponding to this subject matter. The investigation and assessment of changes in the components of the environment are carried out using the environmental approach, i.e. based on a universal connection of processes that occur at different levels of the phenomena studied.

Table 1. Methodological support

\begin{tabular}{|c|c|c|}
\hline $\begin{array}{l}\text { Research } \\
\text { component }\end{array}$ & Quantitative measure & $\begin{array}{l}\text { Methodological } \\
\text { support }\end{array}$ \\
\hline $\begin{array}{l}\text { Anthropogenic } \\
\text { factor }\end{array}$ & $\begin{array}{l}\text { Emission, discharge, } \\
\text { ash and slag waste }\end{array}$ & $\begin{array}{l}\text { Methods for } \\
\text { calculating } \\
\text { emissions }[10-12] \text {, } \\
\text { discharges, and } \\
\text { waste from energy } \\
\text { facilities }[13,14]\end{array}$ \\
\hline $\begin{array}{l}\text { Anthropogenic } \\
\text { impact }\end{array}$ & $\begin{array}{l}\text { Anthropogenic load, } \\
\text { indicators of the } \\
\text { composition } \\
\text { pollutants, of } \\
\text { dangers, climatic and } \\
\begin{array}{l}\text { orographic } \\
\text { characteristics of the } \\
\text { territory }\end{array}\end{array}$ & $\begin{array}{l}\text { Assessment of the } \\
\text { background state of } \\
\text { the environment } \\
\text { components and } \\
\text { information on } \\
\text { their properties. } \\
\text { Systematization of } \\
\text { information on } \\
\text { properties of } \\
\text { energy-related } \\
\text { harmful substances } \\
{[15-17] \text { Climatic }} \\
\text { models describing } \\
\text { physical, } \\
\text { thermodynamic, } \\
\text { and chemical } \\
\text { processes in the } \\
\text { components of the } \\
\text { environment } \\
{[18,19]}\end{array}$ \\
\hline $\begin{array}{l}\text { Anthropogenic } \\
\text { pollution }\end{array}$ & $\begin{array}{l}\text { The concentration of } \\
\text { pollutants, the density } \\
\text { of deposition. }\end{array}$ & $\begin{array}{l}\text { Models of the } \\
\text { spread of pollutants } \\
\text { in various } \\
\text { components of the } \\
\text { environment } \\
\text { (taking into } \\
\text { account the relief } \\
\text { of the underlying } \\
\text { surface) [20-22] }\end{array}$ \\
\hline $\begin{array}{l}\text { The effect of } \\
\text { anthropogenic } \\
\text { pollution }\end{array}$ & $\begin{array}{l}\text { The factor of } \\
\text { exceedance of } \\
\text { maximum permissible } \\
\text { concentrations for } \\
\text { various components of } \\
\text { the environment, } \\
\text { standards for } \\
\text { permissible } \\
\text { emissions/discharges, } \\
\text { etc. }\end{array}$ & $\begin{array}{l}\text { Systematization of } \\
\text { existing quality } \\
\text { standards for each } \\
\text { element of the } \\
\text { environment } \\
\text { 25] }\end{array}$ \\
\hline
\end{tabular}

We propose presenting the concepts, definitions and their relationships graphically as an ontology, which provides the visibility and possibility of harmonizing with the appropriate methods of calculating the quantitative measures of the studied components of the environmental impact of the energy sector.
Various methodological approaches and mathematical models have been developed to assess the negative impact of the energy sector. They are used depending on the task.

The formation of methodological support as a way to quantify the relationships between concepts and phenomena requires the collection and processing of a large amount of information and methodological material. The systematization of methods will allow us to build a clear sequence for both quantitative and qualitative assessment of the energy-related environmental impact.

\section{Acknowledgments}

The results were obtained within the framework of the project under the state assignment of the ISEM SB RAS AAAA-A17-117030310444-2 (project No. 349-2016-0005) and with partial financial support from RFBR grants № 1907-00351, № 20-07-00195.

\section{References}

1. L.V. Massel, I.Yu. Ivanova, T.N. Vorontsova, E.P. Maysyuk, A.K. Izhbuldin, T.G. Zorina, A.R. Barseghyan,. Ontological aspects of the study of mutual influence of energy and Geoecology, Ontology of design, 8, (2018)

2. E.P.Maysyuk, I.Yu. Ivanova. Analysis of existing methods for assessing the impact of energy objects on the environment, Information and Mathematical Technologies in Science and Management, 4 (12), DOI: 10.25729 / 2413-0133-2018-4-12, (2018)

3. Orlov D. S., Sadovnikova L. K., Lozanovskaya I. N. Ecology and protection of the biosphere under chemical pollution, (2000)

4. Goldberg V. M. the Relationship between underground water pollution and the natural environment, L., (1987)

5. Ecological encyclopedia, Chief editor V. I. DanilovDanilyan, M.: LLC "Publishing house "encyclopedia"", 2, (2010)

6. Ecological encyclopedia, / Chief editor A. S. Monin, M.: Publishing house "Noosphere", (1999)

7. T.N. Vorozhtsova, N.N.Makagonova, L.V. Massel. An ontological approach to designing a database to assess the environmental impact of energy, Information and Mathematical Technologies in Science and Management, 3 (15) DOI: 10.25729 / 2413-0133-20193-03. (RSCI). (2019)

8. S.A. Saltykov, E.Yu. Rusyaeva. Ontological Engineering and Philosophy of Management Theory, https://vspu2019.ipu.ru/proceedings/1584.pdf, (2019)

9. Ontological engineering. International Laboratory for Intelligent Systems and Structural Analysis, https://cs.hse.ru/ai/issa/ Field_Ontology_Engineering (2019)

10. Methodology for determining gross emissions of pollutants from boiler plants of thermal power plants. RD 34.02.305-98 / VTI. - M., (1998) 
11. Methodology for determining the emissions of pollutants when burning fuel in boilers with a capacity of fewer than 30 tons of steam per hour or less than 20 Gcal per hour. M.: State Committee on Environmental Protection of the Russian Federation (with the participation of Integral, St. Petersburg), (1999)

12. Guidance letter of the Research Institute of Atmosphere No. 335 / 33-07 dated May 17, 2000, "On the calculation of emissions of harmful substances to the atmosphere according to the" Methodology for determining emissions of pollutants when burning fuel in boilers with a capacity of fewer than 30 tons of steam per hour or less 20 Gcal per hour " (M., 1999). St. Petersburg: Research Institute of Atmosphere, (2000)

13. Yu.G. Nazmeev. Ash and slag removal systems of thermal power plants. - M.: Publishing House MPEI, (2002)

14. Methodological recommendations on the development of draft standards for the maximum waste disposal for thermal power plants, combined heat and power plants, industrial and heating boiler houses of St. Petersburg, http://docs.cntd.ru/document/1200043975 (1998)

15. The list and codes of substances polluting the air. - SPb, Publishing House Petersburg - XXI century, (1995)

16. Y.M. Grushko. Harmful organic compounds in industrial emissions. Reference book - L.: Chemistry, (1986)

17. B.B. Chebanenko, E.P. Maysyuk. Baikal region: limits of sustainability. - Novosibirsk: Nauka, (2002)

18. M.E. Berland. Current problems of atmospheric diffusion and air pollution. L.: Gidrometeoizdat, (1975)

19. N.L. Byzova, E.K. Garger, V.N. Ivanov. Experimental studies of atmospheric diffusion and impurity dispersion calculations. L. Gidrometeoizdat, (1991)

20. Methodology for calculating atmospheric concentrations of harmful substances in the emissions of enterprises. SAD-86. Goskomgidromet. - L., (1987)

21. G.E. Gordon. Receptor models. Critical review, Environ. Sci. Technol, 22(10), (1988)

22. R.R.Draxler, G.D Hess. Description of the HYSPLIT-4 Modeling System.US Environmental Protection Agency Technical Memorandum ERL ARL-224, National Oceanic and Atmospheric Administration, Silver Springs, MD., December (1997)

23. Resolution No. 165 "On approval of hygienic standards GN 2.1.6.3492-17 "Maximum permissible concentrations (MPC) of pollutants in the atmospheric air of urban and rural settlements" (as amended on May 31, 2018), http://docs.cntd.ru/document/556185926, (2017)

24. The maximum permissible concentration of chemicals in the water of water facilities of drinking, cultural and domestic water use. Hygienic standards HS 2.1.5.68998 of the Ministry of Health of Russia, Moscow, http://www.gosthelp.ru/text/GN21568998Predelnodopu sti.html, (1998)
25. Maximum permissible concentrations of chemicals in the soil. Hygienic standards. HS 2.1.7.2041-06. http://www.gosthelp.ru/text/GN217204106Predelnodop ust.html 